\title{
Bilateral Macular Hemorrhage Revealing Severe Thrombocytopenia in an AIDS Context about a Case Report
}

\author{
Angue Tatiana Harly Mba Aki ${ }^{1,2 *}$, Synthia Mekyna ${ }^{1,2}$, Alex Mouigna Abayi ${ }^{2,3}$, \\ Prudence Ada Assoumou ${ }^{1,2}$, Irène Mistoul ${ }^{4}$, Vouma Marjorie ${ }^{3}$, \\ Emmanuel Mve Mengome ${ }^{2,3}$ \\ ${ }^{1}$ Ophthalmology Unit, CHU, Angondje, Gabon \\ ${ }^{2}$ Department of Ophthalmology, Faculty of Medicine, Libreville, Gabon \\ ${ }^{3}$ Army Instruction Hospital, Libreville, Gabon \\ ${ }^{4}$ Infectiology Service, CHU, Libreville, Gabon \\ Email: *mbatati4@yahoo.fr
}

How to cite this paper: Mba Aki, A.T.H., Mekyna, S., Abayi, A.M., Assoumou, P.A., Mistoul, I., Marjorie, V. and Mengome, E.M. (2019) Bilateral Macular Hemorrhage Revealing Severe Thrombocytopenia in an AIDS Context about a Case Report. Open Journal of Ophthalmology, 9, 28-33. https://doi.org/10.4236/ojoph.2019.91004

Received: November 7, 2018

Accepted: January 19, 2019

Published: January 22, 2019

Copyright $\odot 2019$ by author(s) and Scientific Research Publishing Inc. This work is licensed under the Creative Commons Attribution International License (CC BY 4.0).

http://creativecommons.org/licenses/by/4.0/

\begin{abstract}
We report the clinical observation of an HIV-positive/AIDS patient with bilateral macular hemorrhage, which resulted in the identification of severe thrombocytopenia. Thrombocytopenia is a common hematologic anomaly during HIV infection. Its frequency increases with the decrease in CD4 T lymphocytes and the passage to the AIDS stage. Its pathophysiology in this context is complex and multifactorial. Hemorrhagic complications usually appear for platelets less than $50,000 / \mathrm{mm}^{3}$ and this risk is greater at a rate of less than $20,000 / \mathrm{mm}^{3}$. Retinal hemorrhages may go unnoticed, only macular localization results in clinical expression. OCT is of paramount importance in accurate topographic diagnosis of macular hemorrhages by locating their seats which can be pre, intra or under retinal. Management requires the balance of infectious and hematologic factors. Ophthalmic surgical treatments should be considered in a second step.
\end{abstract}

\section{Keywords}

Thrombocytopenia, HIV/AIDS, Hemorrhage, Macula

\section{Introduction}

Macular hemorrhage can complicate several pathologies, such as proliferative diabetic retinopathy, retinal arterial and venous macro-aneurysms, Valsalva retinopathy; retinal venous branch occlusions, trauma and more rarely do hema- 
tologic disorders [1].

Thrombocytopenia is a hematologic disorder which prevalence in adults infected by HIV/AIDS and those free of any antiretroviral therapy is variable according to many studies [2] [3]. The pathophysiological mechanism and etiopathogeny of this hematological disorder during this condition are currently established, with a dual peripheral and central component [4] [5]. These two components give different clinical presentations according to the predominant pathophysiological mechanism. The peripheral thrombocytopenia is precocious, often moderate with severe hemorrhages infrequent. The form of central origin is usually late, deep with a more frequent hemorrhagic syndrome and associated with other Cytopenias [5]. Thrombocytopenia can be discovered during the systematic realization of a $\mathrm{CBC}$ or in the presence of hemorrhagic skin and/or mucous signs. We report the clinical observation of an HIV-positive/AIDS patient with bilateral macular hemorrhage that revealed severe thrombocytopenia.

\section{Observation}

A 30 years old woman consulted for a sudden drop of bilateral visual acuity. She had a six years history of HIV-positive HIV with a notion of refusing antiretroviral therapy. The ophthalmologic examination noted a far visual acuity of far to $3 / 60$ in the right eye and 2/60 in the left eye. The anterior segment was normal and the intraocular pressure was at $12 \mathrm{mmHg}$ in both eyes. The ocular fundus exam revealed a bilateral, oval, dark-colored macular hemorrhage, more prominent on the left, associated with a wide range of retinal juxta-papillary hemorrhage located along the vessels of the superior-nasal quadrant (Figure 1). Fluorescein angiography found a masked effect on hemorrhages (Figure 2). The OCT had made it possible to specify its sub-retinal location (Figure 3). The general clinical examination revealed a significant alteration of the general condition, without any cutaneo-mucous bleeding lesions. The biological assessment noted CD4 T lymphocytopenia at 4 cells $/ \mathrm{mm}^{3}$ and severe thrombocytopenia at $28,000 / \mathrm{mm}^{3}$. After this investigation the diagnosis was bilateral sub-retinal macular hematoma secondary to thrombocytopenia in an HIV positive patient-stage AIDS classified C3 by the Centers for Disease Control (CDC) in Atlanta. The patient had benefited of hematological and infectious care and simple ophthalmic monitoring in a hospital setting. At the infectious level, first-line antiretroviral therapy (Zidovudine, Lamivudine, Nevirapine) and prophylaxis with cotrimoxazole were initiated a few days before corticotherapy. At hematologic level, a two weeks oral corticotherapy with progressive degression was given to reduce platelets to a rate greater than $30,000 / \mathrm{mm}^{3}$ and thus to protect the patient from severe hemorrhage. Prevention of malignant anguillulosis with a pest control was done, as well as calcium and potassium supplementation and gastric protection. After two weeks of follow-up, visual acuity improved to 6/24 in the right eye and 6/18 in the left eye with partial regression of macular and retinal hemorrhage at one month of follow-up, the patient had died as a result of other 




Figure 1. Retinography: Bilateral and asymmetric upper temporal retinal hemorrhage is more important in the right eye associated with a bilateral and asymmetric macular hemorrhage more important on the left eye.

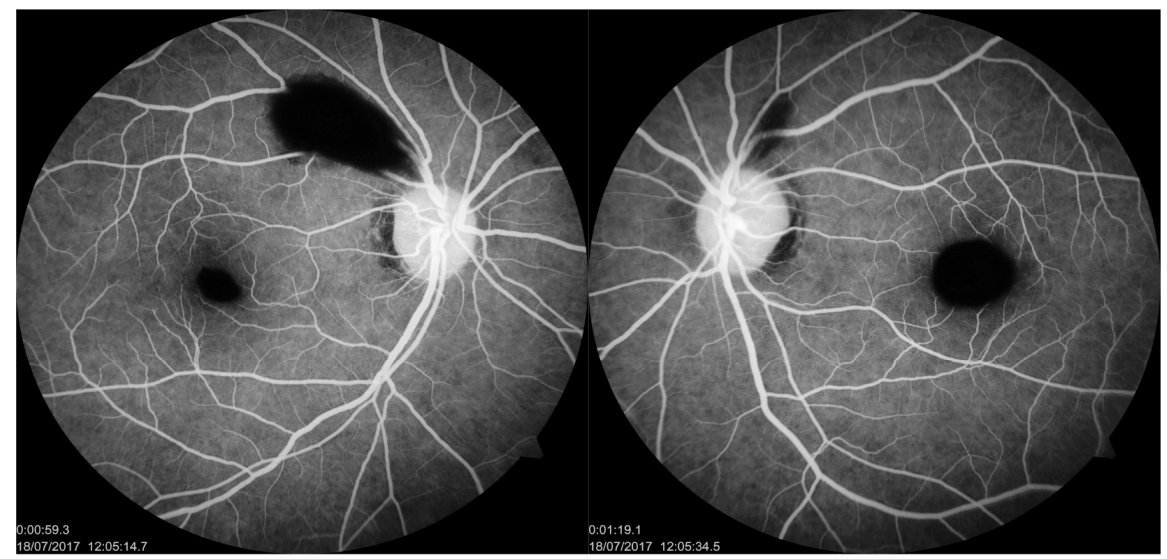

Figure 2. Angiography: Masking effect at the level of hemorrhage, absence of visible vascular abnormalities associated with.
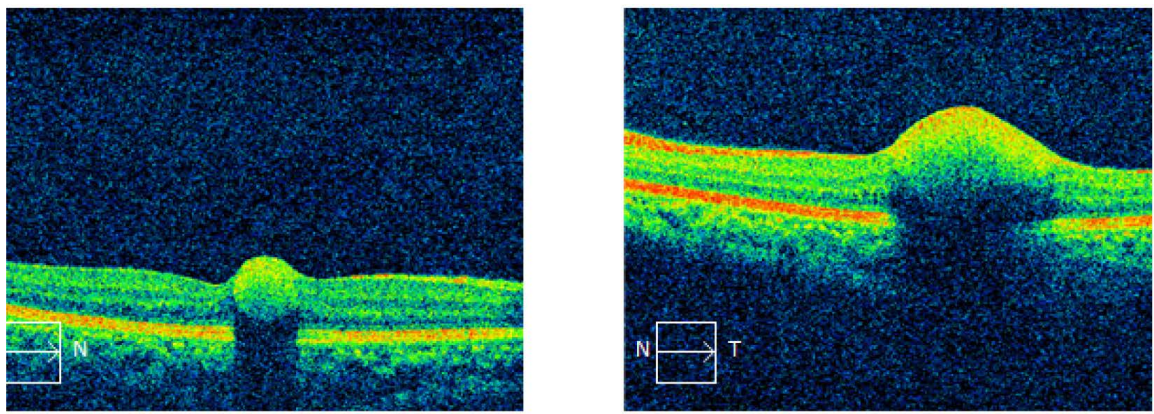

Figure 3. OCT: Bilateral retinal localization of macular hemorrhage.

HIV-related complications. At one month's follow-up, the patient died as a result of lightning herpetic encephalitis.

\section{Discussion}

Thrombocytopenia is a hematologic abnormality that occurs frequently during HIV infection [2] [3]. Its pathophysiology in this context is complex and multi- 
factorial. It may be peripheral in origin, related to a cross-immunity between HIV and platelet glycoproteins or in relation to shorter platelet life span [4] [5]. Thrombocytopenia may also be of central origin due to lack of platelet production either by immunologic mechanisms, opportunistic medullary disorders, drug toxicities or vitamin deficiencies [4] [5]. Hemorrhagic complications generally occur at a platelet count of less than $50,000 / \mathrm{mm}^{3}$ and this risk is greater at a rate of less than $20,000 / \mathrm{mm}^{3}$ [6]. The frequency also increases with the decrease of CD4 T cell count and progression to AIDS [7] [8]. Our patient had accumulated these two important risk factors of hemorrhagic complications. The circumstances in which thrombocytopenia can be detected can be achieved by the systematic completion of a blood count or the presence of hemorrhagic signs [6]. Serious visceral bleeding disorders, whether digestive, cerebro-meningeal or retinal, are exceptional [6]. Retinal hemorrhages may be undetected, only macular localization leads to clinical expression. Indeed, the bilateral macular hematoma responsible for sudden blindness was the mode of revelation of thrombocytopenia in our patient. This is an unusual mode of revelation of thrombocytopenia on a deeply immuno-compromised field. Optical coherence tomography has been of great help in this case, by localizing the exact seat of the hematological collection. Indeed, this examination is of paramount importance in the precise topographic diagnosis of macular hemorrhage by localizing their sites, which can be pre, intra or sub-retinal; it is also an important examination in the evolutionary follow-up [1]. The sub-retinal location of the hemorrhage is usually of bad prognostic no matter the etiologies [9] [10]. In spite of the simple ophthalmological follow up, we nevertheless observed an improvement in visual acuity in our patient, probably because of the management of the infectious and immunological mechanisms involved in thrombocytopenia. Indeed, it has been improved that the reintroduction of antiretrovirals has been shown to lead to a rapid improvement in platelet medullary production [5] [11] [12]. In opposite to other etiologies responsible for sub-retinal hemorrhages, short-term visual recovery was better in this case. However, in the medium term, follow up was not possible because of the patient's death following other complications related to HIV/AIDS. If total macular hemorrhage is not resorbed within 2-3 weeks, there is the possibility of irreversible damage due to the direct toxicity of the red blood cells over the retinal cells and the pigment epithelium [9] [10] [13]. This risk is most important as the hemorrhage is subretinal in relation to the pre-retinal localization [9] [10] [13]. This is a therapeutic emergency when the resorption at 2 weeks of progression of the hematoma is not complete [1] [9]. The management will then require surgery either by drainage of the hematoma with the addition of a tissue activator of the plasminogen ( $\mathrm{rPA}$ ) allowing the liquefaction of the clot, or by displacement of the hematoma to the retinal periphery after intraocular gas injection with or without rPA [1]-[10].

\section{Conclusion}

Macular hemorrhage as a way of revealing thrombocytopenia in an HIV/AIDS 
context is not common. On the one hand, the balance of infectious and hematologic factors must be a priority in the management of this hemorrhage in order to guarantee a visual improvement. On the other hand, it should prevent other hemorrhagic complications that can compromise the vital prognosis. An ophthalmological examination should be systematically prescribed in the case of an HIV/AIDS and thrombocytopenia association.

\section{Conflicts of Interest}

The authors declare no conflicts of interest regarding the publication of this paper.

\section{References}

[1] Errera, M.H., Barale, P.O., Danan-Husson, A., Scheer, S., Girmens, J.F., de Monchy I. and Sahel, J.A. (2008) Intérêt de la tomographie par cohérence optique pour localiser une hémorragie maculaire. A propos de deux cas. Journal Français d Ophtalmologie, 31, e20. https://doi.org/10.1016/S0181-5512(08)74731-4

[2] Fan, H.-W., Guo, F.-P., Li, Y.-J., Li, N. and Li, T.-S. (2015) Prevalence of Thrombocytopenia among Chinese Adult Antiretroviral-Naïve HIV-Positive Patients. Chinese Medical Journal, 128, 459-464.

https://doi.org/10.4103/0366-6999.151078

[3] Taremwa, I.M., Muyindike, W.R., Muwanguzi, E., Boum, Y. and Natukunda, B. (2015) Prevalence of HIV-Related Thrombocytopenia among Clients at Mbarara Regional Referral Hospital, Mbarara, South Western Uganda. Journal of Blood Medicine, 10, 109-113. https://doi.org/10.2147/JBM.S80857

[4] Passos, A.M., Treitinger, A. and Spada, C. (2010) An Overview of the Mechanisms of HIV-Related Thrombocytopenia. Acta Haematologica, 124, 13-18. https://doi.org/10.1159/000313782

[5] Serraj, K., Mecili, M., Housni, I. and Andrès, E. (2011) Cytopénies et virus d'immunodéficience humaine. Médecine Thérapeutique, 17, 183-195.

[6] Ebbo, M., Grados, A., Bernit, E., Harlé, J.R. and Schleinitz, N. (2015) Comment j'explore une thrombopénie de l'adulte. Médecine Thérapeutique, 21, 124-129.

[7] Parinitha, S. and Kulkarni, M. (2012) Haematological Changes in HIV Infection with Correlation to CD4 Cell Count. Australasian Medical Journal, 5, 157-162. https://doi.org/10.4066/AMJ.2012.100

[8] Scaradavou, A. (2002) HIV-Related Thrombocytopenia. Blood Reviews, 16, 73-76. https://doi.org/10.1054/blre.2001.0188

[9] Zghal-Mokni, I., Nacef, L., Yazidi, B., Malek, I., Bouguila, H. And Ayed, S. (2007) Aspects cliniques et évolutifs des hémorragies maculaires secondaires à un macroanévrysme artériel rétinien. Journal Français do Ophtalmologie, 30, 150-154. https://doi.org/10.1016/S0181-5512(07)89565-9

[10] Schweitzer, C., Bonnel, S., Le Mer, Y., Wolff, B., Colin, J. and Sahel, J.A. (2011) Prise en charge chirurgicale des hémorragies sous-rétiniennes secondaires à une vasculopathie polypoïdale. Journal Français d Ophtalmologie, 34, 557.e1-e7. https://doi.org/10.1016/j.jfo.2010.12.004

[11] O’Bryan, T.A., Okulicz, J.F., Bradley, W.P., Ganesan, A., Wang, X. and Agan, B.K. (2015) Impact of the Highly Active Antiretroviral Therapy Era on the Epidemiology of Primary HIV-Associated Thrombocytopenia. BMC Res Notes, 8, 595. 
https://doi.org/10.1186/s13104-015-1548-3

[12] Franzetti, M., Adorni, F., Oreni, L., Van Den Bogaart, L., Resnati, C., Milazzo, L., Antinori, S., Galli, M. and Ridolfo, A.L. (2014) Changes in the Incidence of Severe Thrombocytopenia and Its Predisposing Conditions in HIV-Infected Patients Since the Introduction of Highly Active Antiretroviral Therapy. Journal of Acquired Immune Deficiency Syndromes, 67, 493-498.

https://doi.org/10.1097/QAI.0000000000000347

[13] Toth, C., Morse, L.S., Hjelmeland, L.M. and Landers, M.B. (1991) Fibrin Directs Early Retinal Damage after Experimental Subretinal Hemorrhage. Archives of Ophthalmology, 109, 723-729.

https://doi.org/10.1001/archopht.1991.01080050139046 